with his father, who stated that he was as intelligent and active as before the accident, and quite able to go on with his school work. On examining the skull, there was to be felt a distinct depression about one inch long, and large enough to allow the end of the little finger to lie in it, situated nearly one inch below the parietal eminence, just at the position of the original wound. The boy was quite bright and intelligent, and there was no loss of power or sensibility in any part of the body, neither were any morbid sensations present.

\section{KIDDERMINSTER INFIRMARY.}

COMPOUND DEPRESSED FRACTURE OF SKULL; EXUDATION OF CEREBRAL MATTER; TREPHINING; RECOVERY; REMARKS.

(Under the care of Mr. SPoFFoRTH.)

WE are indebted for the following notes to $\mathrm{Mr}$. Frederic S. Barber, house-surgeon :-

Mary B-, aged twenty-five, was admitted on Nov.11th, at 1.20 A.M. She was unconscious, much collapsed, and bleeding freely from the scalp. On examination it was found that over the left parietal region there was a large lacerated wound leading down to a depressed fracture of the parietal bone near its anterior inferior angle, the depressed portion being about an inch and a half in length at its free edge, and being driven in to the extent of about one-third of an inch. Behind this, and situated over the posterior inferior angle of the parietal bone (and over the lateral sinus), was an incised wound, leading down to a well-marked fracture of the bone, but with no depression. There was also another scalp wound and continuance of the fracture over the longitudinal sinus above the occipital protuberance. From the history, the above had all been produced by an assault with a hatchet. The wounds were dressed with carbolised oil, and restoratives given to the patient, who remained unconscious till about $5.30 \mathrm{A.M}$., when she became dreamily aware of her surroundings and able to answer simple questions. In this state she remained till the forenoon, when Mr. Spofforth proceeded to trephine. On removing the dressings, those coming from the anterior wound were found to be smeared with cerebral matter, and a quantity of cerebral matter was noticed beneath the scalp. In elevating the depressed portion (after removing a semicircular pledget), Mr. Spofforth found it necessary to use his whole force. The wound was loosely sewn up with silver, a small drainage-tube introduced beneath the scalp, having two free ends, and dressed with carbolised oiled lint and absorbent wool. The dressing was allowed to remain undisturbed for fifteen days, at which time the wounds were found to be quite healed (with the exception of the orifices for the tubing), perfectly dry, and a marked absence of purulent discharge. The tubing was withdrawn and a fresh dressing applied as before; afterwards it was freely oiled and lightly protected by a bandage. She complained of much pain at first, which was checked by a one-grain opium pill occasionally, and a calomel purge was given, otherwise she received no medicine. Her mental faculties were not impaired, and all her special senses were perfect. She had inability for voluntary micturition for a few days, but that has since become normal. The highest temperature reached was $100 \cdot 8^{\circ}$ on the fifth day and $100 \cdot 6^{\circ}$ on the eighth day, since which time it became quite normal.

Remarks.-We notice the position of the depressed fracture almost over the middle meningeal and of the posterior one over the lateral sinus; then the evidence of the membranes being ruptured and the cerebral matter exuding, and at the same time apparent absence of meningitis; the continued integrity of all the senses; and the rapid repair of the parts, with scarcely any suppuration.

The Rivers Committee have presented a report to the Manchester City Council in which, after careful consideration of the question of the best method for the treatment and disposal of the sewage of Manchester, it is recommended that they be authorised to make inquiries and report as to the land which can be obtained at a reasonable rate for carrying out either the irrigation or precipitation system, and to report to the Council the result of such inquiries, together with particulars of the scheme to be adopted for the complete interception of the drainage of the city.

\section{想edical Societies.}

ROYAL MEDICAL AND CHIRURGICAL SOCIETY.

\section{Displacement and Fracture of the Axis.-The Radical Cure of Club-foot.}

AN ordinary meeting of this Society was held on Tuesday last, Dr. George Johnson, F.R.S., President, in the chair. The following gentlemen were elected Fellows of the Society: Drs. W. D. Halliburton, F. W. Mott, Theodore D. Acland, A. Haig, Messrs. James Berry, John Cahill, W. M. Collins, F. H. Hawkins, K. W. Millican, and J. Poland.

A paper on a case of Displacement and Fracture of the Axis was read by Dr. DAvID Lowson. The paper was communicated to the Society by Sir Prescott Hewett, Bart. The injury occurred ten years ago to a man aged seventy-five, who fell on the vertex of his skull from a wall six feet high. After recovering consciousness, the patient experienced great pain in the neck. The head was bent back and carried stiffly. Nasal respiration was obstructed, and the mouth kept open to render respiration easier. Deglutition was difficult; the voice had a nasal intonation; and a hard swelling could be seen and felt projecting from the back of the pharynx. There was no paralysis or anæsthesia. The patient died in July, 1884, from a disease having no connexion with the injury. At the post-mortem examination it was found that the axis was bent back to an angle of $60^{\circ}$ the bodies of the second and third vertebræ were ankylosed, and the arch of the third was partially telescoped into that of the second, to which it had become ankylosed. The cord was gently bent opposite the site of the injury, and the spinal canal at this point was quite wide and roomy. The specimen was exhibited to the Society, and also a somewhat similar one from the St. Bartholomew's Hospital Museum. It appeared that Sir James Paget had discovered a specimen of displacement and fracture of the axis in a churchyard, and Sir Prescott Hewett had had two cases similar to the one here recorded.-The Presidnent referred to the rarity of this injury, and to the obstruction of the cesophagus caused by the projection of the displaced bodies of the vertebræ.-Mr. ADAMs asked whether any attempt was made to put the neck straight. There need be no fear of doing harm by straightening the neck in cases which were usually partial unilateral dislocations of the neck; symptoms referable to injury of the cervical nerves were generally present. Three cases were briefly related which had been treated by him by immediate extension and complete rest.--Mr. NOBLE Surrth said he had seen one case of this injury, and there was a projection in the region of the second or third cervical vertebra. The patient was placed under chloroform, and the neck was restored to its normal shape without disaster. Reference was made to certain specimens in the museums of the hospitals, showing the conditions resulting from caries of the body of cervical vertebræ.-Dr. Lowson said, in reply, that his patient suffered but little, and so really required no surgical interference. His case was one of injury, and he had said nothing as to the consequences of disease of the cervical vertebræ.

A paper on the Radical Cure of Club-foot was read by Mr. RICHARD DAvY. The author arranged his subject under the following heads:- -1 . The line of thought that has induced operative procedures in cases of intractable club-foot. 2. The cases especially suited for operation. 3. The operation itself, the description of its details, and the instruments necessary for its performance. 4. The list of twenty-six cases operated on by the author, and notes of other cases operated on by other surgeons. 5. The exhibition of casts taken before and after operation, and also of living specimens or the results gained. Also six specimens of the blocks of bone removed by the operations. 6. General observations on club-foot, with conclusions. The author considered that his operation was founded on the experiment made on the dead body of freely opening the transverse joint, twisting the foot into varus position, and inserting into the transwerse tarsal joint a wedge. This demonstration justified the removal of the cuboid bone on the living subject in 1874, and, in addition, the base of the fifth metatarsal bone in 1875 . The instruments and splint used by the author were exhibited, and his method of operating and after-treatment described. The open-air 